\title{
THE USE OF SENTINEL 1/2 VEGETATION INDEXES WITH GEE TIME SERIES DATA IN DETECTING LAND COVER CHANGES IN THE SINOP NUCLEAR POWER PLANT CONSTRUCTION SITE
}

\author{
E. Çolak ${ }^{1 *}$, M. Chandra ${ }^{1}$, F. Sunar ${ }^{2}$ \\ ${ }^{1}$ Chemnitz University of Technology, Germany (emre.colak, madhu.chandra)@etit.tu-chemnitz.de \\ 2 ITU, Civil Engineering Faculty, Geomatics Engineering Department, 80626 Maslak Istanbul, Turkey fsunar@itu.edu.tr
}

KEY WORDS: Nuclear Power Plant, Sentinel 1/2 Data, SAR Vegetation Indices, Google Earth Engine (GEE), Change Detection.

\begin{abstract}
:
Recently, the demand for nuclear power plants has been increasing in developing countries in line with global energy demands. Turkey, one of the developing economies, is also making plans for nuclear power generation since 1970. The Sinop Nuclear Power Plant was a planned nuclear plant located in the Turkey's most northern point in an area where $99 \%$ of the land is forest, in Sinop Peninsula. If disputes are resolved and its construction continues, the plant is expected to be put into service in 2028. On the other hand, due to the construction of the nuclear power plant, the land cover in and around the plant site has changed, potentially causing major environmental changes. As an example, more than 650000 trees have been cut down so far for the construction of a nuclear power plant, which may have a negative impact on the region's ecological balances by endangering biodiversity and causing ecological damage. The aim of this study is to detect changes in forest areas from the start of nuclear power plant construction through December 2020 using Sentinel 1 SAR and Sentinel 2 optical time series images. For this purpose, different radar and optical vegetation indices such as Modified Radar Vegetation Index (mRVI), Modified Radar Forest Degradation Index (mRFDI), and Normalized Difference Vegetation Index (NDVI) were applied using Google Earth Engine (GEE) Sentinel 1/2 satellite time series for 2015-2020 period. As a result, the indices used were found to yield findings consistent with the reported negative land cover change. In addition, correlation analysis were made between the radar vegetation indices used and a very high negative correlation (-0.99) was found. The annual distributions of the values of the three indices used were statistically evaluated using boxplots.
\end{abstract}

\section{INTRODUCTION}

In recent years, global energy demand has increased rapidly all over the world, especially in developing countries. Given the global energy demand, high power supply capability, and low fuel levels needed for service, nuclear energy is a viable power source for developing countries (Prăvălie and Bandoc, 2018; Cardin et al., 2017). Nuclear energy, which is used for electricity, is one of the most controversial alternative energy sources on the market because of its benefits and drawbacks. The main reason for this is that nuclear safety has become a global concern, especially in the aftermath of disasters like the Fukushima nuclear power plant explosion in Japan in 2011 (Çolak et al., 2019).

Despite the continuing concerns about long-term waste disposal, nuclear power remains a viable source of electricity. According to International Energy Agency (2020), in emerging market and developing economies, nuclear power output will increase by over $60 \%$ from 2019 to 2030 . The fleet of nuclear reactors in advanced economies will shrink over the next decade, while emerging market and developing economies will gain the most additional capacity (International Energy Agency, 2020) (Figure $1)$.

At the beginning of 2020, $42 \mathrm{GW}$ of nuclear power capacity was under construction (out of $62 \mathrm{GW}$ globally), and by 2030 , nuclear power capacity is expected to increase from $110 \mathrm{GW}$ to around $180 \mathrm{GW}$. Most of the currently planned reactors are located in Asia, with fast-growing economies and rapidly growing electricity demand. In this context, China is on track to overtake the United States and the European Union as the world leader in nuclear power by 2030 (International Energy Agency, 2020).

*Corresponding Author

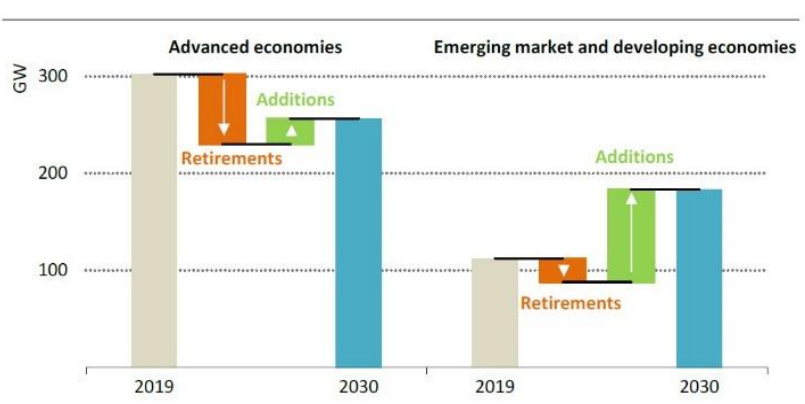

Figure 1. Nuclear power installed capacity, capacity additions and retirements in advanced and developing economies between the years 2019 and 2030 (International Energy Agency, 2020).

Turkey, one of the developing economies, is also making plans for nuclear power generation since 1970. Turkey commenced construction of its first $20 \mathrm{GW}$ nuclear power plant in Mersin, Akkuyu in April 2018, with start of operation expected in 2023. Now two more nuclear power plants are scheduled to be held in Turkey. However, the construction plans of other two power plants, especially the Black Sea province of Sinop, were stopped many times. Because of this three nuclear power plant installation plans, there is opposition and a strong anti-nuclear movement across Turkey, especially in Sinop, which has been heavily affected by radioactive fallout since the Chernobyl nuclear accident in 1986. Nature protection zones close to the Sinop, such as Hamsilos National Park, which has a diverse range of plant and animal species as well as fertile land, would, on the other hand, be negatively impacted. Furthermore, fisheries are expected to suffer as a result of the Sinop Nuclear Power Plant's cooling water being supplied from the Black Sea (28 million cubic meters per day), which provides $10 \%$ of Turkey's overall fish consumption (Çolak et al., 2019). Besides, since Turkey is 
geographically located in earthquake-prone areas, it should be noted that there is a need for higher safety standards in the construction and service processes, based on new methods, standardization, and quality systems (Çolak et al., 2019; International Energy Agency, 2020).

Currently, the construction of the Sinop Nuclear Power Plant has been stopped due to a negative feasibility study report and cost analysis. Although it is currently suspended on June 27, 2019, monitoring environmental changes during nuclear power plant construction is critical and necessary, for both assessing potential adverse environmental impacts (e.g. air pollution, biodiversity loss, genetic contamination, loss of landscape /aesthetic degradation, soil contamination, etc.) and generating reliable/relevant data and time series to further enable safety assessments, traceability, and preservation (Çolak et al., 2019). In this context, space technologies, such as remote sensing, offer tools for collecting data on land use/land cover (e.g. vegetation quality and quantity) and can provide a practical method for mapping environmental changes. Especially, high performance cloud computing platforms, such as Google Earth Engine (GEE), that provide free access to multi-temporal (time series) satellite data are useful tools for land use/ land cover change monitoring. GEE time series can be computed without the need for a priori scene selection, which significantly speeds up the time required to produce satellite data sets within a predetermined date range.

The main purpose of this study is to detect changes in forest areas from the start of nuclear power plant construction through December 2020 using multi-temporal Sentinel 1 SAR and Sentinel 2 optical images. For this purpose, different radar and optical vegetation indices such as Modified Radar Vegetation Index (mRVI), Modified Radar Forest Degradation Index (mRFDI), and Normalized Difference Vegetation Index (NDVI) were applied using GEE Sentinel 1/2 satellite time series for 2015-2020 period and results were evaluated statistically.

\section{STUDY AREA}

The Sinop Nuclear Power Plant is a planned nuclear plant located in the Turkey's most northern point in an area where $99 \%$ of the land is forest, in Sinop Peninsula (Figure 2). The nuclear power plant planned to be built in partnership with France and Japan was signed in 2013. However, the agreement with Japan has ended and negotiations with other suppliers for the construction of nuclear power plants are still ongoing.

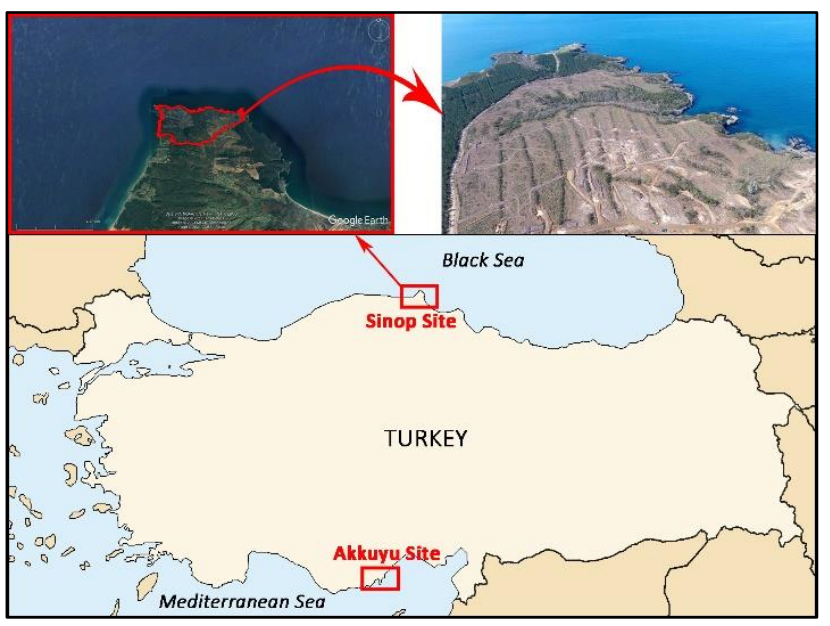

Figure 2. The map and images of the Sinop nuclear power plant.
The Sinop Nuclear Power Plant is designed to have a 4,480megawatt capacity of electricity generation with four reactors, each with a 1,120-megawatt capacity. It will be the country's second nuclear power plant after the projected Akkuyu nuclear power plant on the Mediterranean coast. The area of 10.1 square kilometres allocated for the nuclear power plant is close to nature protection zones; i.e. adjacent to Bozburun Wildlife Development Area; $3.1 \mathrm{~km}$ from Hamsilos Nature Park that is the only fjord of the Black Sea, $4.9 \mathrm{~km}$ from Aksaz-Karagöl Wetland and $4.2 \mathrm{~km}$ from Sarıkum Nature Reserve (Çolak et al., 2019). The project, which has been stopped four times due to strong antinuclear protests, is currently suspended due to financial disputes. However, it is reported that more than 650000 trees have been cut so far for the construction of the nuclear power plant. According to the authorities, the trees here are about 40 years old and have been cut according to the shaving method (Cebeci, 2019). If nuclear power plant construction takes place, this will radically change the land cover around the power plant site, causing significant environmental and ecological destructions.

The rapid changes in forest areas are clearly visible in the Sentinel-2 2015 and 2020 NDVI images given in Figure 3. These preliminary findings clearly point to forest destruction in this area

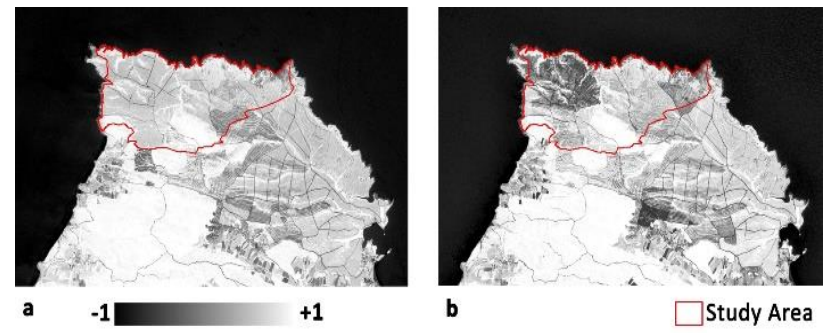

Figure 3. Sentinel-2 NDVI images of the study area for a) 2015 , and b) 2020 .

\section{DATA COLLECTION}

Multi-temporal Sentinel 1 images (dated from August 13, 2015 to December 26, 2020) and Sentinel 2 images (dated from August 6,2015 to December 29, 2020) were used in the analysis. Sentinel 1 consists of a SAR instrument operating in band C (3.75-7.5 $\mathrm{cm}$ ) and L1 GRD (Ground Range Distance) level, according to IW mode with the polarizations (VH) and (VV) was used (Table 1) (ESA-Sentinel, 2018).

\begin{tabular}{|c|c|c|c|c|}
\hline $\begin{array}{c}\text { Acquisition } \\
\text { mode }\end{array}$ & $\begin{array}{c}\text { Product } \\
\text { type }\end{array}$ & $\begin{array}{c}\text { Resolution } \\
\text { Range } \mathrm{x} \\
\text { Azimuth (m) }\end{array}$ & $\begin{array}{c}\text { Number } \\
\text { of looks }\end{array}$ & Polarization \\
\hline \multirow{2}{*}{ IW } & GRD & $10 \times 10$ & $5 \times 1$ & \multirow{2}{*}{ VH } \\
\cline { 3 - 4 } & $40 \times 40$ & $22 \times 5$ & VV \\
\hline
\end{tabular}

Table 1. The characteristics of the Sentinel 1 data used (ESA-Sentinel 2018).

For Sentinel 2, the bands; 3 (Red) and 8 (NIR) which have $10 \mathrm{~m}$ spatial resolution were used to produce NDVI. All dataset were obtained using the GEE platform.

\section{METHODOLOGY \& APPLICATION}

Various image-processing steps and analysis such as preprocessing, vegetation indices, and statistical analysis, were applied in GEE platform to evaluate the results of forest 
destruction quantitatively and qualitatively, as shown in the flow chart (Figure 4).

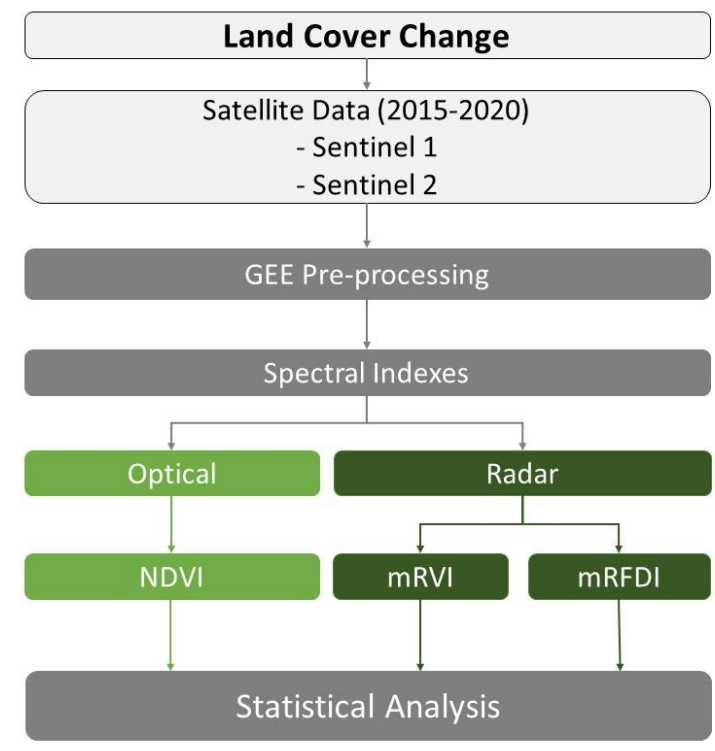

Figure 4. Flowchart of the study.

\subsection{GEE Pre-processing}

Before generating the time series in GEE for Sentinel 1, a preprocessing step was applied. The pre-processing steps include thermal noise removal, radiometric calibration, speckle filtering, and subsetting of an image to the extent of study area. For Sentinel 2, the dataset was also subsetted according to the study area.

\subsection{Optical Vegetation Indices}

Using spectral reflectance measurements, various spectral indices have been established for qualitative and quantitative evaluation of vegetation biomass. Since it is a measure of photosynthetic behaviour, plant greenness, and condition, the Normalized Difference Vegetation Index (NDVI) is the most commonly used vegetation index (Akkartal et al., 2004; Çolak et al., 2019). It is calculated according to the equation stated below.

$$
N D V I=\frac{N I R-R e d}{N I R+R e d}
$$

where NIR is the Near Infrared band.

\subsection{Radar Vegetation Indices}

Besides the optical data, polarimetric Synthetic Aperture Radar (SAR) data provides an effective and reliable way to gather information needed to extract forest bio-physical parameters. SAR data are known to be affected by changes in these parameters such as forest type and structure, moisture and phenology; and these effects are seen as a change in radar backscatter. Similar to optical spectral indices, there are also SAR vegetation indices such as Radar Vegetation Index (RVI) and Radar Forest Degradation Index (RFDI) that take these parameters into account and are very useful in monitoring forest resources (Table 2).

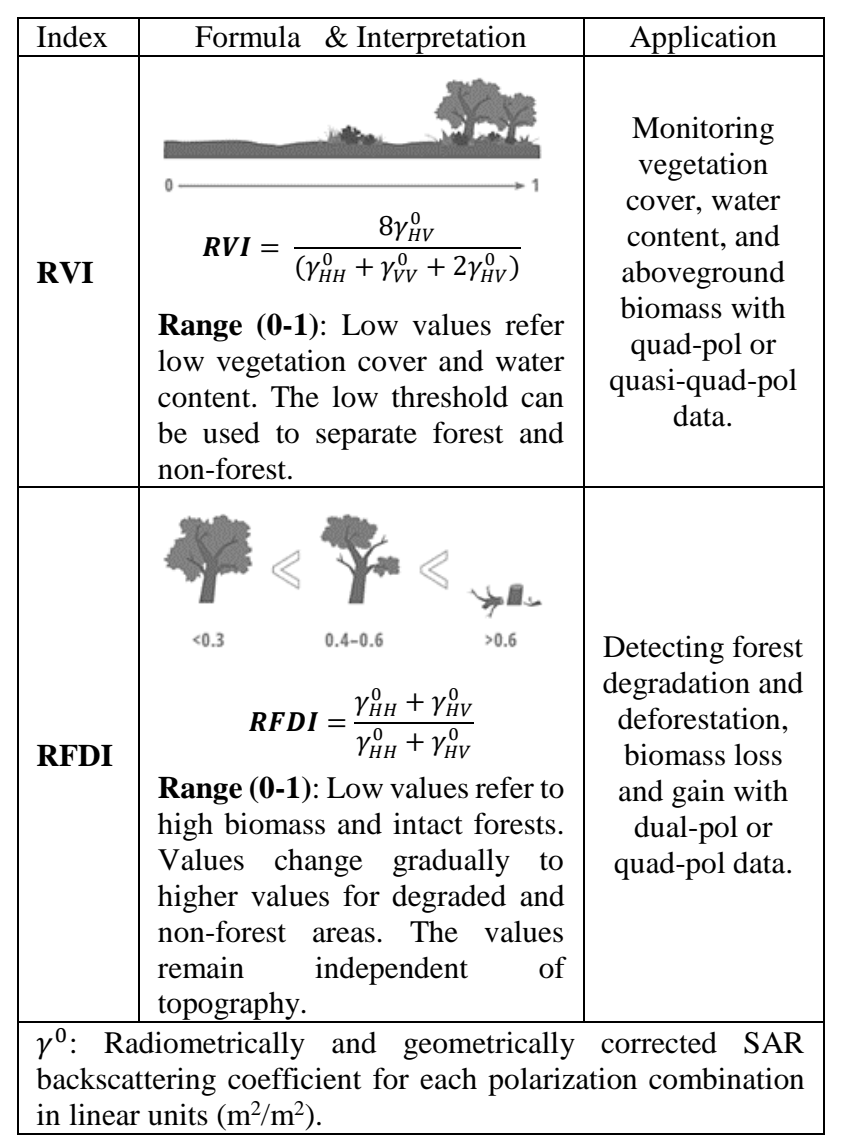

Table 2. SAR vegetation indices used (Flores et al., 2019; Servirglobal, 2019).

RVI is the ratio of cross polarization to total power from all polarization channels. It is a measure of scattering randomness and ranges between 0 and 1 . RVI is close to zero for a smooth bare surface. On the other hand, it increases with vegetation growth. It has high sensitivity to biomass and vegetation cover. $\mathrm{RVI}$, as a ratio, is less sensitive to radar measurement geometry and topography and is insensitive to absolute calibration errors in radar data (Flores et al., 2019). RVI is suitable for quad-pol SAR data, but since Sentinel 1 SAR data has dual polarization (VV and $\mathrm{VH}$ ), the modified version for dual-pol SAR data i.e. the Modified Radar Vegetation Index (mRVI) (Agapiou, 2020) was used in this study. The formulation of mRVI is given as follows.

$$
m R V I=\left(\frac{\gamma_{V V}^{0}}{\gamma_{V V}^{0}+\gamma_{V H}^{0}}\right)^{0.5}\left(\frac{4 \gamma_{V H}^{0}}{\gamma_{V V}^{0}+\gamma_{V H}^{0}}\right)
$$

On the other hand, RFDI is mainly used to monitor and detect degradation and recovery of forest cover. RFDI values range from 0 to 1 , and in general, RFDI values less than 0.3 indicate dense forests, 0.4 to 0.6 degraded forests, and higher than 0.6 deforestation. Low values indicate forests where the effect of the volume-surface interaction is small (i.e. forests with shorter stems and dense canopies) or relatively equal in both channels (i.e. forests above the slopes). Higher values refer to forests with large differences between $\mathrm{HH}$ and $\mathrm{HV}$, open or recently degraded forests or inundated forests. RFDI can be used at any spatial resolution; however, the best spatial resolution for developing RFDI depends on the speckle noise in radar backscatter (Flores et al., 2019). However, in this study, a modified version of the Modified Radar Forest Degradation Index (mRFDI) was used for 
dual-pol SAR data such as Sentinel-1 data. The formulation of mRFDI is given as follows (Nicolau et al., 2021).

$$
m R F D I=\frac{\gamma_{V V}^{0}-\gamma_{V H}^{0}}{\gamma_{V V}^{0}+\gamma_{V H}^{0}}
$$

\subsection{Statistical Analysis}

In the statistical analysis, firstly time series were created and trends were determined. Then, correlation analysis was performed between the radar indices used. In addition, for statistical analysis, the annual averages of the images were taken and the data ranges were evaluated statistically using boxplots.

- Correlation analysis: The simplest method to examine the relationship between two variables is correlation analysis. The Pearson's correlation coefficient, abbreviated R, is a basic statistical method used in remote sensing applications to quantify the degree of association between linearly related variables. It is determined by dividing the covariance of the two variables by the product of their standard deviations (Chen et al., 2018).

- Annual distributions of the indices: The annual distributions of the indices are shown in boxplots. Boxplots are graphs that demonstrate the skewness and distribution of numerical data by showing the data quartiles and averages.

\section{RESULTS}

\subsection{Optical Vegetation Indices}

Sentinel-2 NDVI time series was generated in GEE platform between the years 2015 and 2020 (Figure 5).

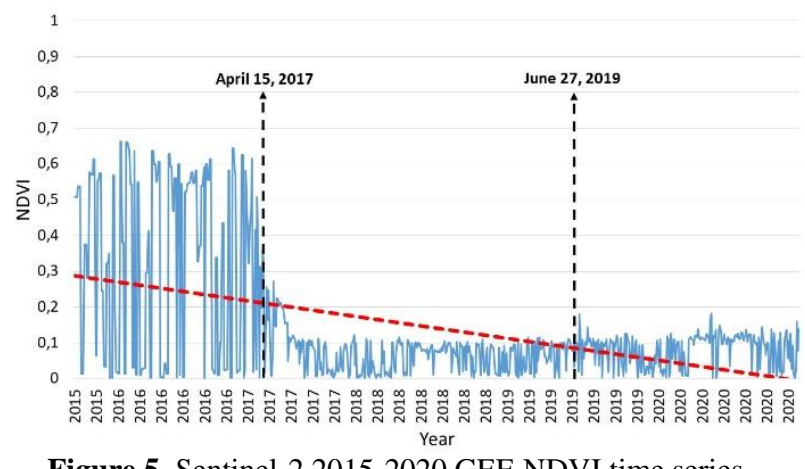

Figure 5. Sentinel-2 2015-2020 GEE NDVI time series.

As can be seen in Figure 5, NDVI values up to April 15, 2017 show a similar trend in the study area. On the other hand, the decline in the NDVI time series is evident after April 15, 2017, when the trees in the region began to be cut down. From this date until December 2020, NDVI values are very low (0.01-0.18).

In Figure 6, the seasonal average of NDVI values is shown as a time series in order to see the seasonal changes. As can be seen in this image, the cutting of trees is clearly visible after April 15, 2017. However, after the project was suspended (27 June 2019), there is a slight increase in NDVI values.

Since the nuclear project is a sensitive issue in Turkey, there is not enough information from official sources regarding the current situation and developments in the region after the suspension. For this reason, it is thought that either small shrubs re-emerged spontaneously or partial afforestation was made.

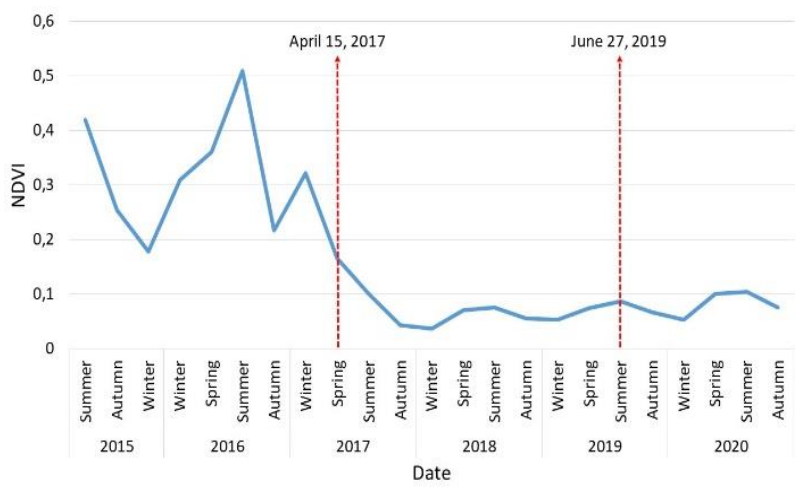

Figure 6. Sentinel-2 2015-2020 GEE seasonal average NDVI time series.

\subsection{Radar Vegetation Indices}

Weather-independent radar vegetation indices (mRVI and mRFDI) derived from SAR data are an alternative to NDVI generated from optical data. To show forest destruction clearly indicated by the NDVI data, also with these radar vegetation indices, Sentinel $1 \mathrm{mRVI}$ and mRFDI time series were created using the GEE platform as in the NDVI time series (Figure 7).

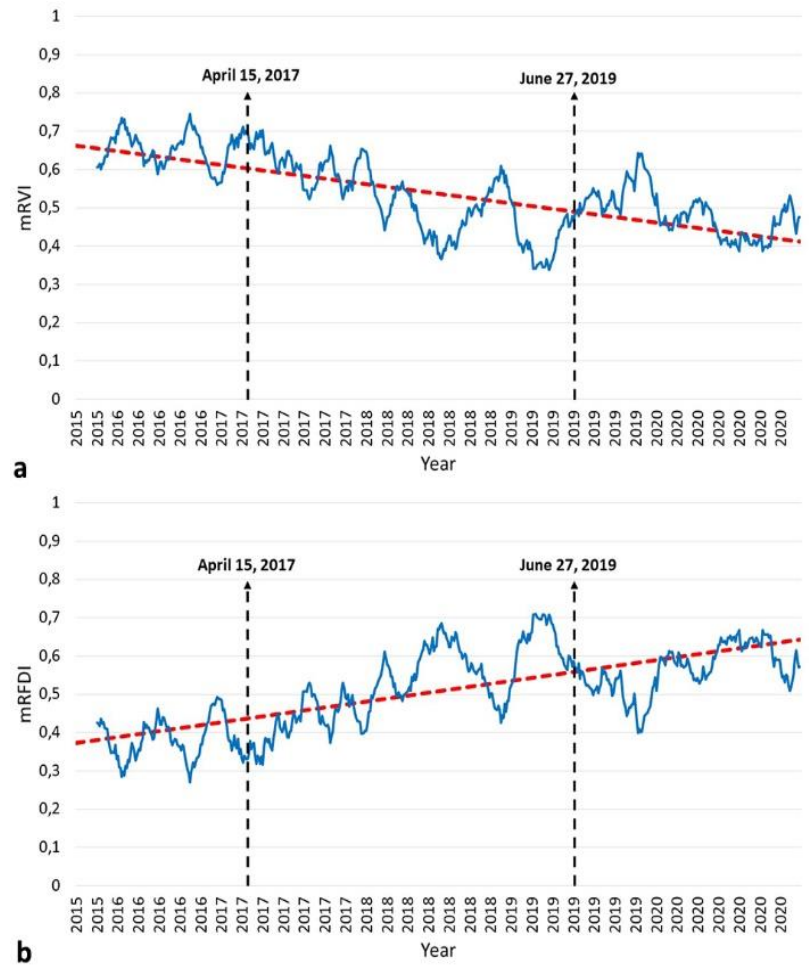

Figure 7. Sentinel-1 2015-2020 GEE a) mRVI and b) mRFDI time series.

As seen in Figure 7a, there is a decrease in mRVI after the forest destruction on April 15, 2017. It is known that low mRVI values refer low vegetation cover. It is also clearly seen that the downward trend continues until December 2020. There is also an increase in mRFDI values, which high mRFDI values indicate open or recently degraded forests (Figure 7b). Similarly, it is seen that the upward trend in this index continues until December 2020 . 
Similarly, in Figure 8, seasonal average of radar vegetation indices are also shown as a time series in order to see the seasonal changes.

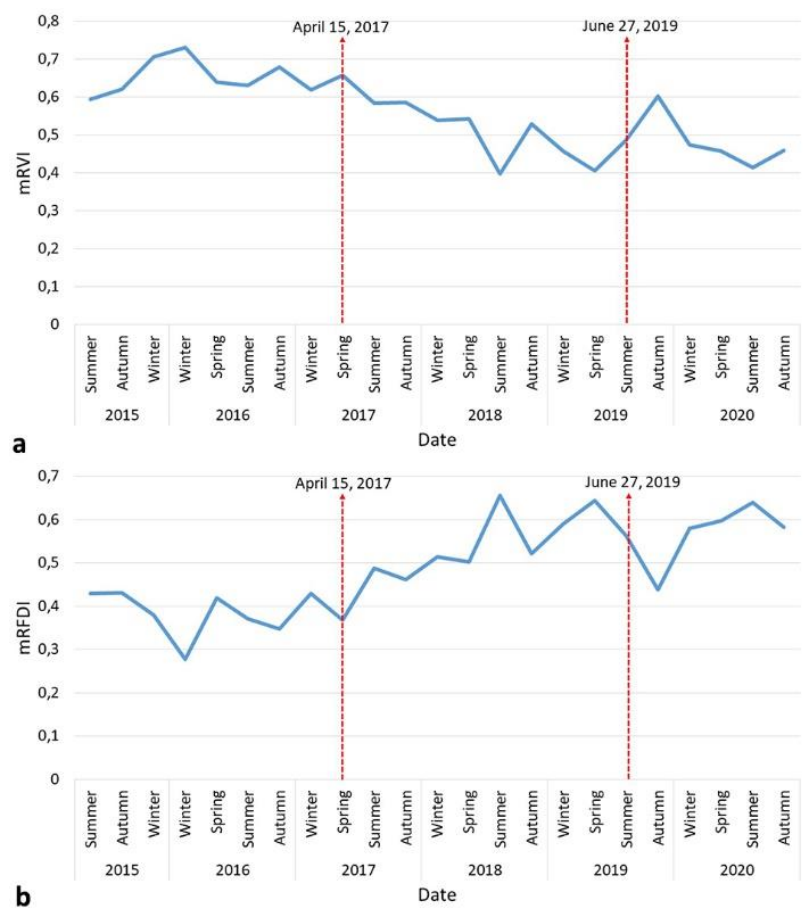

Figure 8. Sentinel-1 2015-2020 GEE seasonal average a) mRVI and b) mRFDI time series.

When looking at the two seasonal average radar vegetation time series (Figure 8), there seems to be an improvement especially on November 4, 2019. This improvement is thought to be due to the germination or re-emergence of small shrubs after suspension date, since after November 2019, the values decreased for mRVI (Figure 8a) and increased again for mRFDI (Figure 8b).

It is obvious that these two radar vegetation indexes successfully show the land cover change. They are suitable alternatives for NDVI, which is particularly affected by cloudy weather.

\subsection{Statistical Analysis}

\section{- Correlation Analysis}

The Pearson correlation coefficient was used to conduct a correlation analysis between the radar vegetation indices to determine the strength of the relationship. Therefore, the relationship between radar vegetation indices $\mathrm{mRVI}$ and $\mathrm{mRFDI}$ was measured by Pearson correlation coefficient (Figure 9).

It is clear that there is a high correlation $(\mathrm{R}=-0.99)$ between mRVI and mRFDI. The high correlation coefficient of these indices obtained from radar data indicates that vegetation and forest monitoring can be applied efficiently with these two indices.

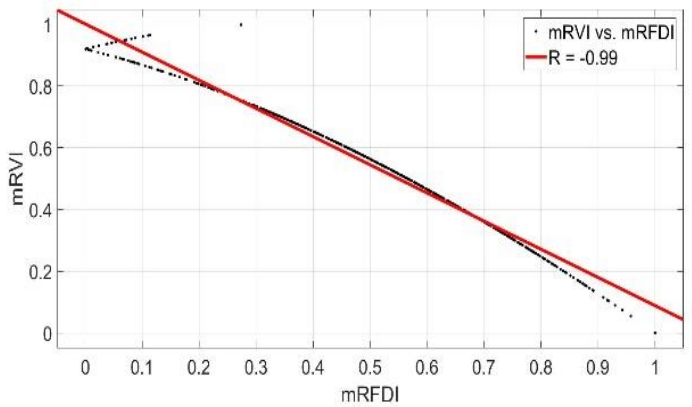

Figure 9. Correlation analysis between mRVI and mRFDI.

\section{- Annual Distributions of the Indices}

Boxplots were created to see the distribution of the optical and radar vegetation indices, NDVI, mRVI, and mRFDI, annually in the Figures 10, 11 and 12, respectively.

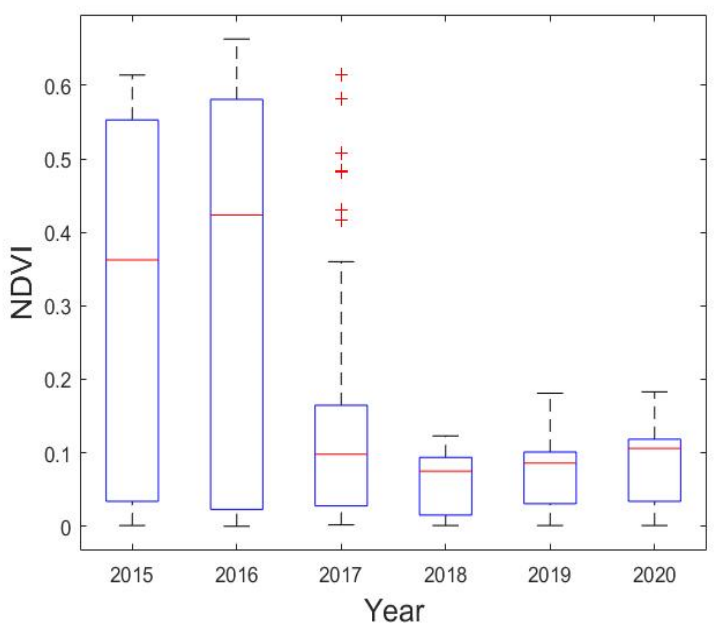

Figure 10. Boxplot of annual NDVI.

As seen from Figure 10, the land cover change of the study area in NDVI values is clearly visible. It is obvious that the NDVI distributions in 2015 and 2016 varied approximately between 0 and 0.6. This shows that there is a healthy forest biomass in the area. However, it is seen that the distribution decreased between 0 and 0.2 with the cutting of trees that started in 2017. Outliers, marked in red, showing observations that are numerically far from the rest of the data are also visible in 2017. This situation shows that forest cutting has been done gradually since 2017 .

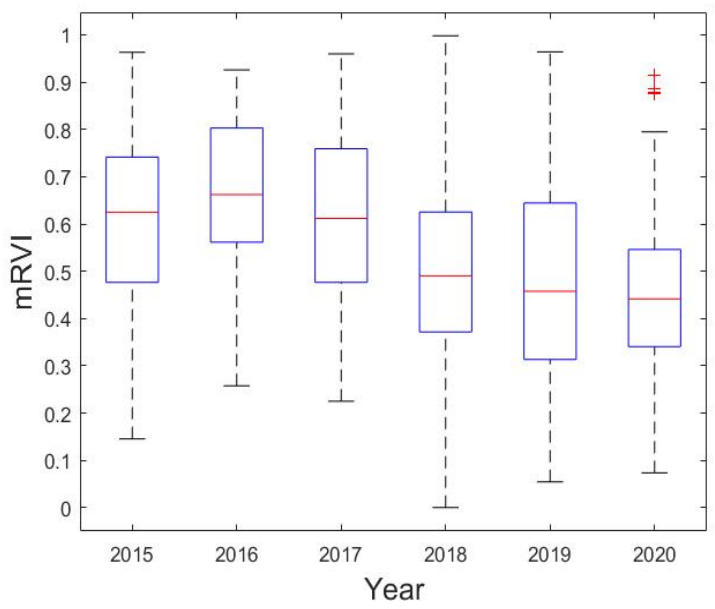

Figure 11. Boxplot of annual mRVI. 
Similar to NDVI, a gradual decrease can be observed in mRVI after 2017 (Figure 11). This is easier to understand, especially from the median of the distribution (marked in red in the middle of the distribution). A decrease in values to 0.4 in mRVI indicates that almost all tree structure has been destroyed in this area (Table 2).

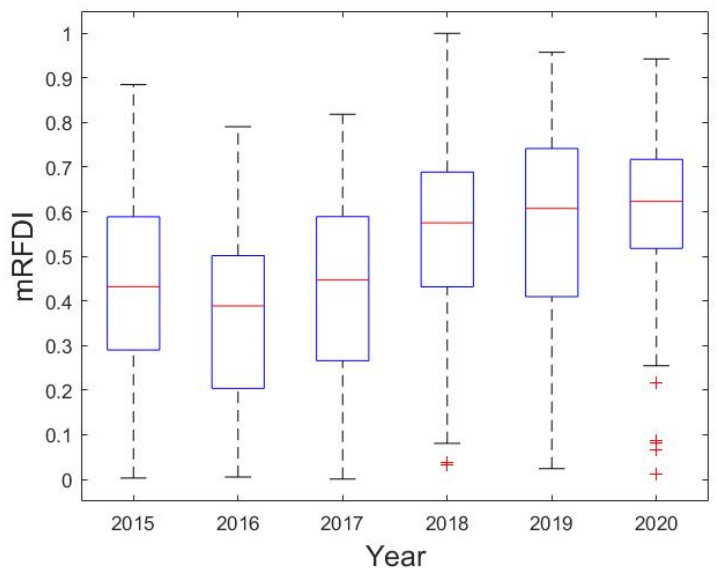

Figure 12. Boxplot of annual mRFDI.

In mRFDI, it is seen that the values increase year by year. If the values exceed 0.6 , it again indicates the disappearance of the tree structure (Figure 12).

\section{CONCLUSION}

Turkey, like other emerging and developing economies in recent years, wants to benefit from nuclear energy sources to improve both economic and social prosperity. However, feasibility studies regarding the environmental costs/consequences they may face should be done carefully, i.e. without endangering their ecosystems or causing ecological damage.

As shown in this study, complementary optical and radar Sentinel time series images are very useful for accurate land use/land cover change mapping of environmentally sensitive areas. In this context, high-performance cloud computing platforms such as GEE, that provide free access to time series satellite data, are particularly important and required in the analysis. As shown, time series of optical and radar vegetation indices such as NDVI, mRVI and mRFDI produced at GEE have successfully demonstrated forest change in the study area.

A high correlation coefficient (-0.99) was found between mRVI and mRFDI, which states that there is a very high relationship between these radar vegetation indices. In addition, the increase and / or decrease in the annual distribution of the optical and radar vegetation indices is clearly shown with boxplots, which are a basic statistical tool.

Finally, two main findings are drawn from this study; i) Sentinel 1 and 2 images, while having different spectral domains, provide different but complementary information about forest degradation and loss, ii) GEE offers a very practical and successful solution for monitoring land cover change with time series. As a continuation of this study, it is aimed to monitor deforestation by extracting more useful spectral features together with optical vegetation indices from Sentinel 1 SAR data using deep learning techniques.

\section{REFERENCES}

Agapiou, A., 2020. Estimating Proportion of Vegetation Cover at the Vicinity of Archaeological Sites Using Sentinel-1 and -2 Data, Supplemented by Crowdsourced OpenStreetMap Geodata. Appl. Sci. 10, 4764.

Akkartal, A., Türüdü, O., Sunar Erbek, F., 2004. Analysis of Changes in Vegetation Biomass Using multitemporal and Multisensor Satellite Data. In XXXV ISPRS Congress, 12-23. 2004.

Cebeci, B., 2019. Sinop’ta nükleer santral çalışması durdu: "Ağaçların kesildiği alanın beton yığınına dönüşmesinden endişe ediyoruz" [Nuclear power plant operation stopped in Sinop: "We are concerned that the area where the trees are cut will turn into a concretion"]. https://medyascope.tv/2019/06/28/sinoptanukleer-santral-calismasi-durdu-agaclarin-kesildigi-alaninbeton-yiginina-donusmesinden-endise-ediyoruz/ (30 June 2016).

Cardin, M. A., Zhang, S., Nuttall, W. J., 2017. Strategic Real option and flexibility analysis for nuclear power plants considering uncertainty in electricity demand and public acceptance. Energy economics 64, 226-237.

Chen, W., Zhang, S., Li, R., Shahabi, H., 2018. Performance evaluation of the GIS-based data mining techniques of best-first decision tree, random forest, and naïve Bayes tree for landslide susceptibility modeling. Science of The Total Environment (644), 1006-1018. https://doi.org/10.1016/j.scitotenv.2018.06.389.

Çolak, E., Chandra, M., Sunar, F., 2019. The Use of MultiTemporal Sentinel Satellites in the Analysis of Land Cover/Land Use Changes Caused By the Nuclear Power Plant Construction. Int. Arch. Photogramm. Remote Sens. Spatial Inf. Sci., Xlii3/W8, 491-495, Https://Doi.Org/10.5194/Isprs-Archives-Xlii-3W8-491-2019.

Flores, A., Herndon, K., Thapa, R. B., Cherrington., 2019. The SAR Handbook: Comprehensive Methodologies for Forest Monitoring and Biomass Estimation, https://doi.org/10.25966/nr2c-s697.

International Energy Agency, 2020. World energy outlook 2020.

Prăvălie, R., Bandoc, G., 2018. Nuclear energy: between global electricity demand, worldwide decarbonisation imperativeness, and planetary environmental implications. Journal of environmental management 209, 81-92.

Nicolau, A.P., Flores-Anderson, A., Griffin, R., Herndon, K., Meyer, F.J., 2021. Assessing SAR C-band data to effectively distinguish modified land uses in a heavily disturbed Amazon forest. International Journal of Applied Earth Observation and Geoinformation 94, https://doi.org/10.1016/j.jag.2020.102214.

Servirglobal, 2019. SAR Vegetation Indices. https://servirglobal.net/Portals/0/Documents/Articles/2019_S R_Handbook/SAR_Vegetation\%20Indices_one-pager.pdf ${ }^{-}$(26 November 2019). 